\title{
Electronic delocalization in two and three dimensions: differential aggregation in indium 'metalloid' clusters
}

\begin{abstract}
Andrey V. Protchenko, a Juan Urbano, ${ }^{\mathrm{a}, \mathrm{b}}$ Joseph A.B. Andrew D. Schwarz, ${ }^{a}$ Matthew P. Blake, ${ }^{a}$ Philip Moun

Abstract: Reduction of indium boryl precursors to give two- and three-dimensional $\mathrm{M}-\mathrm{M}$ bonded networks is influenced by the choice of supporting ligand. While the unprecedented nanoscale cluster $\left[\mathrm{In}_{68}(\text { boryl })_{12}\right]^{-}$(with an $\operatorname{In}_{12} @ \mid \mathrm{I}_{44} @ \ln \mathrm{n}_{12}(\text { bory })_{12}$ concentric structure), can be isolated from the potassium reduction of a bis(boryl)indium(III) chloride precursor, analogous reduction of the corresponding (benzamidinate) $\mid \mathrm{n}^{\mathrm{II}} \mathrm{Br}$ (boryl) system gives a nearplanar (and weakly aromatic) tetranuclear $\left[\ln _{4}(\text { boryl })_{4}\right]^{2-}$ system.
\end{abstract}

Metal-metal bonded compounds of aluminium and gallium have been the subject of a number of landmark studies in the last 20 years, ${ }^{[1]}$ ranging from dimetallic systems such as $\left\{\left(\mathrm{Me}_{3} \mathrm{Si}\right)_{2} \mathrm{CH}\right\}_{2} \mathrm{AIAI}\left\{\mathrm{CH}\left(\mathrm{SiMe}_{3}\right)_{2}\right\}_{2}{ }^{[2]}$ and the 'digallyne' $\mathrm{Na}_{2}\left[\mathrm{Ar}^{\text {Trip }}{ }_{2}\right.$ $\left.\left.\mathrm{Ga}_{2}\right] \quad\left(\mathrm{Ar}^{\text {Trip }}=2,6-\left(2,4,6-{ }^{i} \mathrm{Pr}_{3} \mathrm{C}_{6} \mathrm{H}_{2}\right)_{2} \mathrm{C}_{6} \mathrm{H}_{3}\right)\right),{ }^{[3]}$ through planar trinuclear systems of the type $\mathrm{Na}_{2}\left[\mathrm{Ar}^{\mathrm{Mes}}{ }_{3} \mathrm{M}_{3}\right]\left(\mathrm{M}=\mathrm{Al}, \mathrm{Ga}\right.$; $\mathrm{Ar}^{\mathrm{Mes}}=$ 2,6-(2,4,6- $\left.\left.-\mathrm{Me}_{3} \mathrm{C}_{6} \mathrm{H}_{2}\right)_{2} \mathrm{C}_{6} \mathrm{H}_{3}\right),{ }^{[4]}$ all the way to large 'metalloid' clusters such as $\left[\mathrm{Al}_{77}\left\{\mathrm{~N}\left(\mathrm{SiMe}_{3}\right)_{2}\right\}_{20}\right]^{2-}$ and $\left[\mathrm{Ga}_{84}\left\{\mathrm{~N}\left(\mathrm{SiMe}_{3}\right)_{2}\right\}_{20}\right]^{n-}(n$ $=3,4) \cdot{ }^{[5,6]}$ Such systems have proved pivotal to the evolution of theories of chemical bonding for the heavier $p$-block elements, in particular for the formulation of delocalized bonding models in one, two and three dimensions. Thus, intense debate concerning the bond order in $\mathrm{Na}_{2}\left[\mathrm{Ar}^{T r i p}{ }_{2} \mathrm{Ga}_{2}\right]$ and related transbent alkyne analogues ultimately led to a fuller understanding of their electronic structure and the unusual ('transition metal like') reactivity displayed by some such systems. ${ }^{[7]}$ In addition, planar $2 \pi$ electron metallacycles have pushed the boundaries of what is understood by 'aromatic' character, ${ }^{[8,9]}$ and larger concentric polyhedral clusters have been identified as nanoscale models for bulk metallic phases. ${ }^{[10]}$

Related compounds featuring the heavier metals of group 13 (i.e. indium and thallium) are much less well known, with In-In bonded systems being dominated by dinuclear In" systems of the type $R_{2} \ln \mid n R_{2}$ and tetrahedral $\operatorname{In}^{\prime}$ systems of the type

[a] Dr A. V. Protchenko, Dr J Urbano, Dr J.A.B. Abdalla, Dr J. Campos, Dr D. Vidovic, Dr A.D. Schwarz, Dr M.P. Blake, Prof P. Mountford, Prof S. Aldridge

Inorganic Chemistry Laboratory, Department of Chemistry, University of Oxford, South Parks Road, Oxford, OX1 3QR, UK E-mail: simon.aldridge@chem.ox.ac.uk

[b] Dr J. Urbano

Departamento de Química y Ciencia de los Materiales, CIQSO, Edificio Robert H. Grubbs, Campus de el Carmen, Universidad de Huelva, Spain

[c] Dr J. Campos

Instituto de Investigaciones Químicas (IIQ), Consejo Superior de Investigaciones Científicas (CSIC) and Universidad de Sevilla, Avda. Américo Vespucio, 49, 41092 Sevilla, Spain

[d] Dr D. Vidovic

SPMS-CBC, Nanyang Technological University, 21 Nanyang Link, Singapore 637371

[e] Prof C. Jones

School of Chemistry, PO Box 23, Monash University, Melbourne, VIC 3800, Australia

Supporting information for this article is given via a link at the end of the document. Structural data has been deposited with the CCDC (ref: 1563288-1563299)
$\mathrm{R}_{4} \mathrm{In}_{4}{ }^{[11]}$ Planar systems offering the potential for Hückel-type aromaticity, and concentric polyhedral clusters are unknown: the largest polynuclear indium system yet reported to our knowledge is a compound of composition $\ln _{19} X_{6},{ }^{[119]}$ which features a cubicclose-packed $\ln _{13}$ core closely related to the tetragonal structure of the metal itself.

Recently we have been exploiting the extremely sterically demanding boryl ligand $\left[\mathrm{B}(\mathrm{NDippCH})_{2}\right]$ as an ancillary donor for the stabilization of novel main group metal systems, ${ }^{[11 p, 11 q, 12,13]}$ and in the current contribution report on its use for the encapsulation of highly reduced indium clusters with widely differing degrees of nuclearity.

Reduction of the In'I bisboryl complex $\operatorname{In}\left\{\mathrm{B}(\mathrm{NDippCH})_{2}\right\}_{2} \mathrm{Cl}$ with $\mathrm{Cp}^{*}{ }_{2} \mathrm{Sm}$ (thf) has previously been shown to offer clean access to the $\operatorname{In}^{\prime \prime}$ radical $\operatorname{In}\left\{\mathrm{B}(\mathrm{NDippCH})_{2}\right\}_{2}{ }^{[11 \mathrm{p}]}$ The corresponding chemistry using a more aggressive reductant such as potassium metal, also leads to the formation of the $\mathrm{In}^{\text {" }}$ complex (albeit in lower yields), but also to the formation of more highly reduced species, including indium metal itself, and a metalloid cluster of the composition $\left[\ln _{68}(\text { boryl })_{12}\right]^{\top}$, which can be isolated in very low yield and characterized by X-ray crystallography (Figure 1). ${ }^{[14]}$ Aspects of the geometric structure of this cluster are reminiscent of the landmark $\left[\mathrm{Al}_{77}\left\{\mathrm{~N}\left(\mathrm{SiMe}_{3}\right)_{2}\right\}_{20}\right]^{2-}$ system reported by Schnöckel in 1997..$^{[5 a]}$ Thus, the $\ln _{12} @ \ln _{44} @ \ln _{12}(\text { boryl })_{12}$ formulation revealed crystallographically features an icosahedral $\ln _{12}$ unit and surrounding $\ln _{44}$ shell similar to those found in the $\mathrm{Al} @ \mathrm{Al}_{12} @ \mathrm{Al}_{44} @ \mathrm{Al}_{20}$ (amido) ${ }_{20}$ system. Presumably the lower nuclearity of the outermost shell (containing 12 indium atoms, as opposed to 20 aluminiums) reflects the greater steric bulk of the attached $\mathrm{B}(\mathrm{NDippCH})_{2}$ ligands, compared to $\mathrm{N}\left(\mathrm{SiMe}_{3}\right)_{2}$. The other substantive difference is the absence of a central metal atom in $\left[\ln _{68}(\text { boryl })_{12}\right]^{-}$ with no significant $q$-peak being located in the $\mathrm{X}$-ray structure

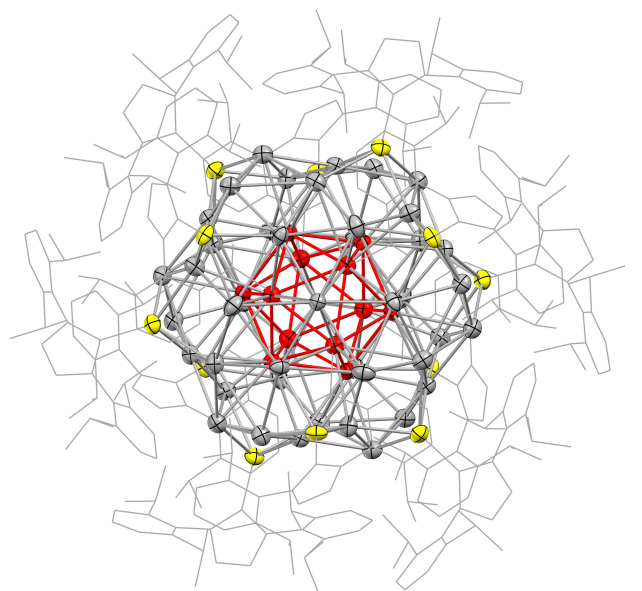

Figure 1. One of the anionic components of $\left[\mathrm{Li}_{9} \mathrm{In}_{6}{ }_{6}\left\{\mathrm{~B}(\mathrm{NDippCH})_{2}\right\}_{6}(\mathrm{Cl})(\mathrm{OH})_{13}\right]^{+}$ $\left[\ln _{68}\left\{\mathrm{~B}(\mathrm{NDippCH})_{2}\right\}_{12}\right]^{-}$in the solid state as determined by X-ray crystallography (see SI for full details). Other anion/cation pair and hydrogen atoms omitted and boryl ligands shown in wireframe format for clarity. The colour scheme reflects the $\ln _{12} @ \ln _{44} @ \ln _{12}(\text { boryl })_{12}$ structure, with the central $\ln _{12}$ icosahedron shown in red, the surrounding shell of 44 non-ligated In atoms shown in grey 
and the outer 12 boryl-bound indium centres shown in yellow. The cluster is shown orientated along its crystallographic six-fold rotation axis. refinement close to the centre of the $\ln _{12}$ icosahedron $(R$ factor $=$ 0.07 ). While a number of metalloid clusters of this type featuring concentric shells of metal atoms - have been reported for aluminium and gallium, ${ }^{[5,10]}$ no significant precedent exists for indium, with the closest analogue being an $\ln _{19}$ (boryl $)_{6}$ system which features a cubic-close-packed $\ln _{13}$ core. ${ }^{[11 q]}$ The icosahedral $\ln _{12}$ core of $\left[\ln _{68}(\text { boryl })_{12}\right]^{-}$features a relatively narrow range of $I n-I n$ bond lengths [3.100(1)-3.145(2) $\AA]$, and can be put in context by the corresponding distances measured for the $M_{12}$ cores of related aluminium and gallium systems (e.g. 2.650-2.762 $\AA$ for $\left.\left[\mathrm{Al}_{22} \mathrm{Br}_{20} \text { (thf) }\right)_{12}\right]$ and 2.593-2.614 $\AA$ for $\left.\left[\mathrm{Ga}_{22} \mathrm{Br}_{2}\left\{\mathrm{~N}\left(\mathrm{SiMe}_{3}\right)_{2}\right\}_{10} \mathrm{Br}_{10}\right]^{2-}\right)$ with due consideration of the metallic radii of the respective elements (Al: $1.43 \AA$; Ga: $1.40 \AA$; In: $1.58 \AA){ }^{[15]}$

In order probe the potential role of the ancillary ligands in mediating the reduction process(es), we targeted the use of chelating ancillary ligands, hypothesizing that such systems might reduce the extent and/or rate of metal-metal aggregation processes. Strong $N, N^{\prime}$-chelating mono-anionic donors such as amidinato, guanidinato and $\beta$-diketiminato ligands have previously been applied to the stabilization of low-valent main group compounds. ${ }^{[16]}$ We therefore targeted the synthesis and reduction chemistry of group 13 systems of the type (amidinato) $\mathrm{E}$ (boryl) $\mathrm{X}(\mathrm{X}=\mathrm{Cl}, \mathrm{Br}) .^{[17,18]}$ In the event, such systems prove to be readily accessible for $\mathrm{E}=\mathrm{Al}, \mathrm{Ga}$ and $\mathrm{In}$, via metathesis chemistry utilizing the corresponding amidinato element dihalide, $\left\{\mathrm{PhC}\left(\mathrm{N}^{i} \mathrm{Pr}\right)_{2}\right\} E \mathrm{E}_{2}(1-\mathrm{EX})$ and one equivalent of Yamashita's boryllithium reagent (thf $)_{2} \mathrm{Li}\left\{\mathrm{B}(\mathrm{NDippCH})_{2}\right\}$ (Scheme 1). ${ }^{[12]}$ Only in the case of the boron-containing precursor $1-\mathrm{BBr}$ is any divergence observed from this pattern of reactivity, with an alternative product being formed resulting from $\mathrm{C}$ - rather than $\mathrm{B}$ centred attack by the boryl nucleophile (Scheme 1 and Figure 2). ${ }^{[19]}$ For aluminium, gallium and indium, however, the respective mono-boryl products 2-AICl, 2- $\mathrm{GaCl}, 2-\mathrm{GaBr}$ and 2$\mathrm{InBr}$ can be accessed via E-B bond formation, and each has been characterized by standard spectroscopic, analytical and (with the exception of 2-GaBr) crystallographic methods. Structurally, each of 2-AICl, 2-GaCl and 2- $\mathrm{InBr}$ (see Figure 2 and
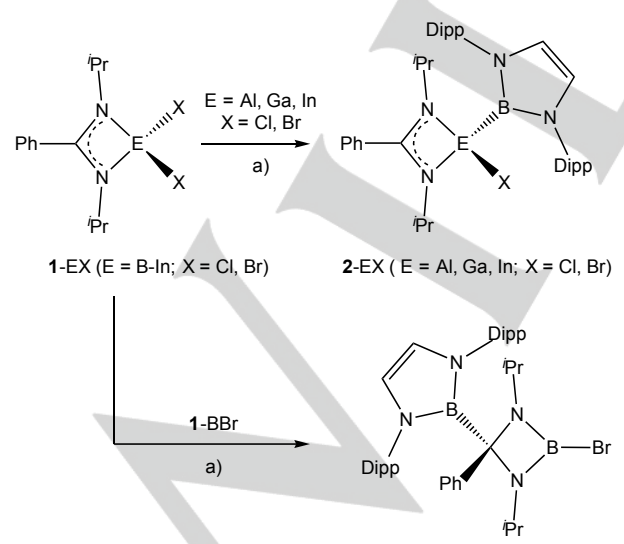

Scheme 1. Reactions of benzamidinato-stabilized Group 13 halides with the boryllithium reagent (thf $)_{2} \mathrm{Li}\left\{\mathrm{B}(\mathrm{NDippCH})_{2}\right\}$ : syntheses of boryl-

aluminium, -gallium and -indium complexes of type $\mathbf{2}$, and backbone-borylated diamido-bromoborane 3 . Key reagents and conditions: a) (thf $)_{2} \mathrm{Li}\left\{\mathrm{B}(\mathrm{NDippCH})_{2}\right\}$ (1 equiv.), benzene, $2 \mathrm{~h}, 20-55 \%$.

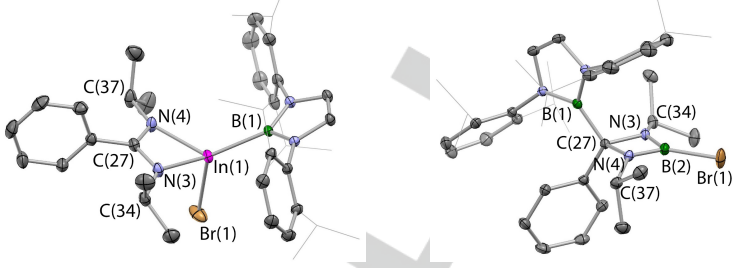

Figure 2. Molecular structures of $2-\ln B r$ (left) and $\mathbf{3}$ (right) in the solid state as determined by X-ray crystallography. Hydrogen atoms omitted and Dipp i Pr groups shown in wireframe format for clarity; thermal ellipsoids shown at the $35 \%$ probability level. Key bond lengths $(\AA)$ and angles $\left({ }^{\circ}\right)$ : (for $\left.2-\ln B r\right): \ln (1)$ $\mathrm{B}(1)$ 2.223(1), $\ln (1)-\mathrm{Br}(1)$ 2.545(1), $\ln (1)-\mathrm{N}(3)$ 2.187(1), In(1)-N(4) 2.179(1), $\mathrm{N}(3)-\mathrm{C}(27)-\mathrm{N}(4)$ 114.3(1), N(3)-In(1)-N(4) 61.3(1); (for 3): B(1)-C(27) 1.614(2), $\mathrm{B}(2)-\mathrm{Br}(1)$ 1.926(2), B(2)-N(3) 1.410(2), B(2)-N(4) 1.412(2), N(3)-B(2)-N(4) 95.7(1), N(3)-C(27)-N(4) 87.4(1).

ESI) features the expected $N, N^{\prime}$-chelating benzamidinate ligand and a four-coordinate metal geometry. The E-B distances $[2.114(2) / 2.111(2), 2.062(2) / 2.064(2)$ and 2.223(1) $\AA$, respectively] are consistent with the presence of conventional 2-centre 2-electron covalent bonds, being similar to those previously reported for boryl complexes of the respective group 13 metals in the +3 oxidation state [e.g. Al: $2.150(2), 2.119(2) \AA ;{ }^{[16 a]} \mathrm{Ga}$ : 2.067(3), 2.098(2) $\AA .^{[16 \mathrm{~b}]}$ In: $\left.\left.2.245(7), 2.256(6) \AA\right]\right]^{[11 \mathrm{p}]}$

With each of these (amidinato)boryl precursors in hand we examined their reduction chemistry towards potassium metal (Scheme 2). In the case of the chloro-aluminium and -gallium systems 2-AICl and 2-GaCl, no molecular group 13 metalcontaining products could be isolated from the reaction mixture, while in the of $2-\mathrm{GaBr}$ we could isolate and structurally characterize trace amounts of a gallium containing species of stoichiometry $\mathrm{Ga}_{2}$ (boryl) ${ }_{2}$ (amidinate), 4 (along with mainly gallium metal; see ESI). The reduction of $2-\mathrm{InBr}$ under similar conditions, however, leads to the formation of a more highly reduced metal-containing system, in accordance with the established redox properties of gallium and indium. ${ }^{[20]}$ As such, NMR measurements are consistent with complete loss of the<smiles></smiles>

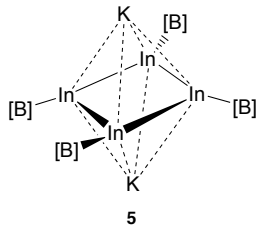

Scheme 2. Reduction of bromo-indium complex $2-\mathrm{InBr}$ with potassium to generate the cyclic tetraindium cluster $\mathrm{K}_{2}\left[\operatorname{In}_{4}\left\{\mathrm{~B}(\mathrm{NDippCH})_{2}\right\}_{4}\right](\mathbf{5})$. $[\mathrm{B}]=$ $\mathrm{B}(\mathrm{NDippCH})_{2}$. Key reagents and conditions: a) $\mathrm{K}$ metal (4.4 equiv.), $\mathrm{C}_{6} \mathrm{D}_{6}$, sonication for $1 \mathrm{~h}, 21 \%$

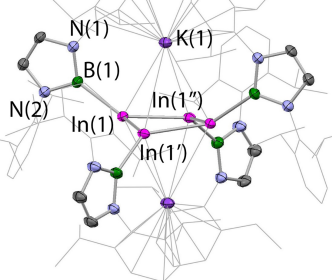

Figure 3. Molecular structure of $\mathbf{5}$ in the solid state as determined by X-ray crystallography. Hydrogen atoms omitted and 'Pr/Dipp groups shown in wireframe format for clarity; thermal ellipsoids shown at the $35 \%$ probability level. Key bond lengths $(\AA)$ and angles $\left({ }^{\circ}\right): \ln (1)-\ln \left(1^{\prime}\right) 2.805(1), \ln (1)-\ln \left(1^{\prime \prime}\right)$ 
2.838(1), $\ln (1)-B(1)$ 2.316(2), $\ln \left(1^{\prime}\right)-\operatorname{In}(1)-\operatorname{In}\left(1^{\prime \prime}\right)$ 89.6(1), $\ln _{4}$ centroid-In(1)-B(1) 148.0

amidinato ancillary ligand. The presence of a single boryl ligand environment is also signalled by ${ }^{1} \mathrm{H}$ NMR measurements, but definitive characterization of the product as the cyclic tetraindium tetraboryl system $\mathrm{K}_{2}\left[\ln _{4}\left\{\mathrm{~B}(\mathrm{NDippCH})_{2}\right\}_{4}\right](5)$ is dependent on the results of X-ray crystallographic studies (Figure 3 ). The solidstate structure features an approximately square array of four (symmetry-related) indium atoms, with each metal centre being additionally bound to a single terminal boryl ligand. The $\ln _{4}$ unit is near-planar, with each indium atom lying $0.12 \AA$ out of the least-squares plane, and the internal In-In-In angles being essentially $90^{\circ}\left[89.6(1)^{\circ}\right.$ in each case]. The structure is completed by two $\mathrm{K}^{+}$counter-ions situated above and below the $\ln _{4}$ unit $\left(\mathrm{K}^{\cdots} \mathrm{In}\right.$ distances: 3.73 and $3.93 \AA$ ), which are sandwiched between the flanking Dipp aryl rings of diagonally opposite boryl ligands. A consequence of these K-arene contacts (3.17-3.37 $\AA$ ) is a slight 'puckering' of the ligand envelope of the $\left[\ln _{4}(\text { boryl })_{4}\right]^{2-}$ unit, such that the $\ln _{4}$ centroid-In-B angles are non-linear $\left[148.0^{\circ}\right]$, and alternate boron atoms are positioned above/below the approximate $\ln _{4}$ plane.

The In-In contacts [2.805(1) and 2.838(1) $\AA$ ] are similar to those found in related systems containing In-In single bonds [e.g $2.777(1) \AA$ for $\left.\ln _{2}\left\{B(N D i p p C H)_{2}\right\}_{3}\right]^{[11 p]}$ and significantly shorter than the intermetallic distances associated with the boryl-ligated indium centres in clusters such as $\ln _{19}\left\{\mathrm{~B}(\mathrm{NDippCH})_{2}\right\}_{6}$ and $\left[\mathrm{In}_{68}\left\{\mathrm{~B}(\mathrm{NDippCH})_{2}\right\}_{12}\right]^{-}$(means: 2.967 and $2.966 \AA$, respectively). ${ }^{[1 \mathrm{q}]}$ The near planar $\ln _{4}$ core of 5 , and the associated 2charge, offers the potential for Hückel aromatic character. ${ }^{[9]}$ Although $2 \pi$ electron metallo-aromatic systems have been reported previously for the lighter congeners aluminium and gallium (for example, $\mathrm{M}_{2}\left[\mathrm{Ga}_{3} \mathrm{Ar}_{3}^{\mathrm{Mes}}{ }_{3}\right](\mathrm{M}=\mathrm{Na}, \mathrm{K}),{ }^{[4 \mathrm{a}, \mathrm{b}]}$ $\mathrm{Na}_{2}\left[\mathrm{Al}_{3} \mathrm{Ar}_{3}^{\mathrm{Mes}}{ }_{3}\right]{ }^{[4 \mathrm{c}]}$ and $\mathrm{K}_{2}\left[\mathrm{Ga}_{4} \mathrm{Ar}^{\text {Trip }}{ }_{2}^{[21]}\right.$, related systems are unprecedented for indium. Superficially, $\mathbf{5}$ is most similar to the silyl-ligated system [(thf) $\mathrm{Na}_{2}\left[\mathrm{Ga}_{4}\left(\mathrm{Si}^{t} \mathrm{Bu}_{3}\right)_{4}\right]$ reported by Wiberg and co-workers, which has been described either in terms of a $2 \pi$ aromatic $\left[\mathrm{Ga}_{4}(\text { silyl })_{4}\right]^{2-}$ dianion, or as a Wade-Mingos five skeletal electron pair $\mathrm{Na}_{2} \mathrm{Ga}_{4}$ bicapped tetrahedron. ${ }^{[22,23]}$ In the case of 5, the latter description (while correct in electron counting terms) is geometrically less appropriate, since the central $\mathrm{In}_{4}$ unit is clearly a long way from being tetrahedral. Thus the $\operatorname{In}-\operatorname{In}-\operatorname{In}-\operatorname{In}$ torsion angles in $\mathbf{5}$ are 9.6 and $9.7^{\circ}$, while the corresponding parameters in the more puckered $\mathrm{Ga}_{4}$ unit of $[(\text { thf }) \mathrm{Na}]_{2}\left[\mathrm{Ga}_{4}\left(\mathrm{Si}^{t} \mathrm{Bu}_{3}\right)_{4}\right]$ are $39.4^{\circ}$.

DFT calculations (carried out at the BP-TZP level) reveal that the HOMO of the $\left[\ln _{4}\left\{\mathrm{~B}(\mathrm{NDippCH})_{2}\right\}_{4}\right]^{2-}$ system is indeed a delocalized $\pi$-type orbital extending in-phase over all four indium centres, with the HOMO-1 possessing In-In $\sigma$-bonding character (Figure 4). The inclusion of the $\mathrm{K}^{+}$counter-cations perturbs the orbital picture slightly: thus for $\mathrm{K}_{2}\left[\mathrm{In}_{4}\left\{\mathrm{~B}(\mathrm{NDippCH})_{2}\right\}_{4}\right]$, greater stabilization of the $\ln -\mathrm{In} \pi$ bonding $\mathrm{MO}$ due to the proximity of the $\mathrm{K}^{+}$cations means that this orbital is the $\mathrm{HOMO}-1$, with the less effectively stabilized o-orbital now being the HOMO. Nucleus Independent Chemical Shift (NICS) values have been calculated for the potassium-free system $\left[\operatorname{In}_{4}\left\{\mathrm{~B}(\mathrm{NDippCH})_{2}\right\}_{4}\right]^{2-}[\mathrm{NICS}(0)=$ $4.92, \operatorname{NICS}(1)=-6.53$ ] and can be compared with the values calculated using the same method for benzene $[\operatorname{NICS}(0)=-7.40$, $\operatorname{NICS}(1)=-9.61] .{ }^{[24]}$ The $\pi$ aromatic character is therefore shown to be relatively weak, ${ }^{[25]}$ presumably reflecting relatively poor $p \pi$ - $p \pi$ overlap for indium, exacerbated by the bending of the boryl substituents away from the $\ln _{4}$ least-squares plane (even in the 'naked' dianion), and hence the imperfectly co-linear arrangement of indium $5 p$ orbitals. Interestingly, a similar, moderately puckered, structure is observed for the related $(6 \pi$-electron) system $\left[\mathrm{Si}_{4}\left(\mathrm{SiMe}^{t} \mathrm{Bu}_{2}\right)_{4}\right]^{2-}$, for which the $\mathrm{NICS}(1)$ value $(+6.1)$ implies a a non-aromatic description. ${ }^{[26]}$

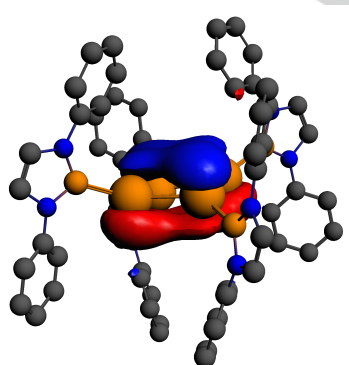

HOMO (+1.85 eV)

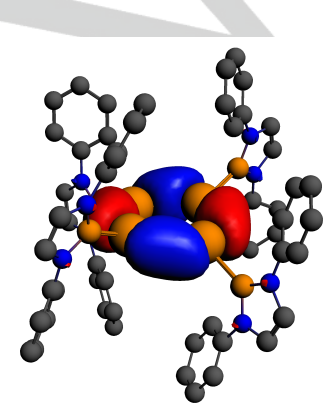

HOMO-1 (+1.64 eV)

$\left[\ln _{4}\left\{\mathrm{~B}(\mathrm{NDippCH})_{2}\right\}_{4}\right]^{2-}$

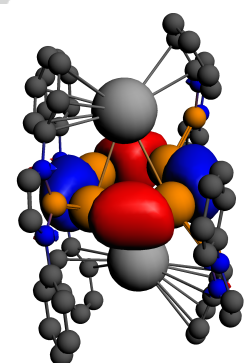

HOMO $(-2.85 \mathrm{eV})$

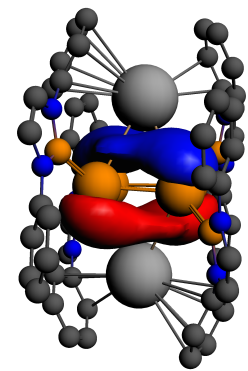

HOMO-1 (-3.24 eV)

$\mathrm{K}_{2}\left[\ln _{4}\left\{\mathrm{~B}(\mathrm{NDippCH})_{2}\right\}_{4}\right]$
Figure 4. Electron density surfaces and energies of key molecular orbitals for $\left[\ln _{4}\left\{\mathrm{~B}(\mathrm{NDippCH})_{2}\right\}_{4}\right]^{2-}$ (left) and $\mathrm{K}_{2}\left[\mathrm{In}_{4}\left\{\mathrm{~B}(\mathrm{NDippCH})_{2}\right\}_{4}\right]$ (right) calculated by Density Functional Theory (see ESI).

In conclusion, we have shown that the highly sterically demanding boryl ligand $\mathrm{B}(\mathrm{NDippCH})_{2}$ is capable of supporting two and three-dimensional aggregates featuring indium in very low oxidation states, including an unprecedented [ $\left[\mathrm{n}_{68}\left(\right.\right.$ bory $\left.\left.\right|_{12}\right]$ concentric cluster and a near planar $2 \pi$-electron cyclic tetramer.

\section{Acknowledgements}

We thank the EPSRC (EP/L025000/1) and the Leverhulme Trust (F/08 699/E) for funding aspects of this work.

Keywords: Group $13 \cdot$ indium $•$ gallium $•$ boryl $\bullet$ metal cluster

[1] For recent reviews see, for example: a) W. Uhl, Adv. Organomet. Chem 2004, 51, 53-108; b) H. Schnöckel, Dalton Trans. 2005, 3131-3136; c) Y. Wang, G. H. Robinson, Organometallics 2007, 26, 2-11; c) E. Rivard, P. P. Power, Inorg. Chem. 2007, 46, 10047-10064; d) J. A. B. Abdalla, S. Aldridge in Molecular Metal-Metal Bonds. Compounds, Synthesis, Properties (Ed.: S. Liddle), Wiley, Chichester, 2015, pp. 455-484.

[2] W. Uhl, Z. Naturforsch. B. 1988, 43, 1113-1118.

[3] J. Su, X.-W. Li, R. C. Crittendon, G. H. Robinson, J. Am. Chem. Soc. 1997, 119, 5471-5472

[4] a) X.-W. Li, W. T. Pennington, G. H. Robinson, J. Am. Chem. Soc. 1995, 117, 7578-7579; b) X.-W. Li, Y. Xie, P. R. Schreiner, K. D. Gripper, R. C. 
Crittendon, C. F. Campana, H. F. Schaefer, G. H. Robinson, Organometallics 1996, 15, 3798-3803; c) R. J. Wright, M. Brynda, P. P. Power, Angew. Chem. Int. Ed. 2006, 45, 5953-5956.

[5] a) A. Ecker, E. Weckert, H. Schnöckel, Nature 1997, 387, 379-381; b) A. Schnepf, B. Jee, H. Schnöckel, E. Weckert, A. Meents, D. Lubbert, E. Herrling, B. Pilawa, Inorg. Chem. 2003, 42, 7731-7733; c) A. Schnepf, H. Schnöckel, Angew. Chem., Int. Ed. 2001, 40, 711-715. For a smaller, but similarly important cluster system, see: d) C. Dohmeier, C. Robl, M. Tacke, H. Schnöckel, Angew. Chem., Int. Ed. 1991, 30, 564-565.

[6] For a review of anionic clusters from the broader $p$-block see, for example: S. Gärtner, N. Korber, Struct. Bonding (Berlin) 2011, 140, $25-$ 57.

[7] a) G. H. Robinson, Acc. Chem. Res. 1999, 32, 773-782; b) Y. Xie, H. F. Schaefer III, G. H. Robinson, Chem. Phys. Lett. 2000, 317, 174-180; c) R. Ponec, G. Yuzhakov, X. Gironés, G. Frenking, Organometallics 2004 23, 1790-1796; d) Z. Zhu, R. C. Fischer, B. D. Elis, E. Rivard, W. A Merrill, M. M. Olmstead, P. P. Power, J. D. Guo, S. Nagase, L. Pu, Chem.-Eur. J. 2009, 15, 5263-5272; e) R. C. Fischer, P. P. Power Chem. Rev. 2010, 110, 3877-3923; f) P. P. Power, Nature 2010, 463 171-177.

[8] a) Y. Xie, P. R. Schreiner, H. F. Schaeffer III, X.- W. Li, G. H. Robinson, J. Am. Chem. Soc. 1996, 118, 10635-10639; b) G. N. Srinivas, A Anoop, E. D. Jemmis, T. P. Hamilton, K. Lammertsma, J. Leszczynski, H. F. Schefer III, J. Am. Chem. Soc. 2003, 125, 16397-16407; c) X. Li, J. Sun, Y. Zeng, Z.Sun, S. Zheng, L. Meng, J. Phys. Chem. A 2012, 116, 5491-5496.

[9] a) X. Li, A. E. Kuznetsov, H. F. Zhang, A. I. Boldyrev, L. S. Wang Science 2001, 291, 859-861; b) A. I. Boldyrev, L.-S. Wang, Chem. Rev. 2005, 105, 3716-3757

[10] See, for example: H. Schnöckel, A. Schnepf in The Group 13 Metals Aluminium, Gallium, Indium and Thallium: Chemical Patterns and Peculiarities (Eds. S. Aldridge, A. J. Downs), Wiley, Chichester, 2011, p 461-471.

[11] For selected In-In bonded systems, see: a) M. A. Khan, C. Peppe, D. G. Tuck, Can. J. Chem. 1984, 62, 601-605; b) W. Uhl, M. Layh, W. Hiller, J. Organomet. Chem. 1989, 368, 139-154; c) R. D. Schluter, A. H. Cowley D. A. Atwood, R. A. Jones, M. R. Bond, C. J. Carrano, J. Am. Chem. Soc. 1993, 115, 2070-2071; d) N. Wiberg, K. Amelunxen, H. Nöth, M. Schmidt, H. Schwenk, Angew. Chem. Int. Ed. 1996, 35, 65-67; e) P. J. Brothers, K. Hübler, U. Hübler, B. C. Noll, M. M. Olmstead, P. P. Power, Angew. Chem. Int. Ed. 1996, 35, 2355-2357; f) W. Uhl, A. Jantschak, W Saak, M. Kaupp, R. Wartchow, Organometallics 1998, 17, 5009-5017; g) N. Wiberg, T. Blank, H. Nöth, W. Ponikwar, Angew. Chem. Int. Ed. 1999, 38, 839-841; h) N. Wiberg, T. Blank, A. Purath, G. Stosser, H. Schnöckel, Angew. Chem. Int. Ed. 1999, 38, 2563-2565; i) B. E. Eichler, N. J. Hardman, P. P. Power, Angew. Chem. Int. Ed. 2000, 39 383-385; j) R. J. Wright, A. D. Phillips, N. J. Hardman, P. P. Power; J. Am. Chem. Soc. 2002, 124, 8538-8539; k) M. S. Hill, P. B. Hitchcock, R. Pongtavornpinyo, Angew. Chem. Int. Ed. 2005, 44, 4231-4235; I) M. S. Hill, P. B. Hitchcock, R. Pongtavornpinyo, Science 2006, 311, 1904$1907 ;$ m) S. P. Green, C. Jones, A. Stasch, Angew. Chem. Int. Ed. 2007, 46, 8618-8621; n) G. Linti, M. Bühler, K. Y. Monakhov, T. Zessin, Dalton Trans. 2009, 8071-8078; o) B. F. T. Cooper, H. Hamaed, W. W. Friedl, M. R. Stinchcombe, R. W. Schurko, C. L. B. Macdonald, Chem. Eur. J. 2011, 17, 6148-6161; p) A. V. Protchenko, D. Dange, J. R. Harmer, C. Y. Tang, A. D. Schwarz, M. J. Kelly, N. Phillips, R. Tirfoin, K H. Birjkumar, C. Jones, N. Kaltsoyannis, P. Mountford, S. Aldridge, Nature Chem. 2014, 6, 315-319; q) A. V. Protchenko, D. Dange, M. P.
Blake, A. D. Schwarz, C. Jones, P. Mountford, S. Aldridge, J. Am Chem. Soc. 2014, 136, 10902-10905; r) M. R. Lichtenthaler, F. Stahl, D. Kratzert, L. Heidinger, E. Schleicher, J. Hamann, D. Himmel, S. Weber, I. Krossing, Nature Commun. 2015, 6, 8288.

[12] a) Y. Segawa, M. Yamashita, K. Nozaki, Science 2006, 314, 113-115; (b) Y. Segawa, Y. Suzuki, M. Yamashita, K. Nozaki, J. Am. Chem. Soc. 2008, 47, 16069-16079.

[13] a) L. M. A. Saleh, K. H. Birjkumar, A. V. Protchenko, A. D. Schwarz, S Aldridge, C. Jones, N. Kaltsoyannis, P. Mountford, J. Am. Chem. Soc 2011, 133, 3836-3839; b) A. V. Protchenko, K. H. Birjkumar, D. Dange, A. D. Schwarz, D. Vidovic, C. Jones, N. Kaltsoyannis, P. Mountford, S. Aldridge, J. Am. Chem. Soc. 2012, 134, 6500-6503; c) A. V. Protchenko, D. Dange, A. D. Schwarz, C. Y. Tang, N. Phillips, P. Mountford, C. Jones, S. Aldridge, Chem. Commun. 2014, 50, 3841-3844; d) A. V. Protchenko, M. P. Blake, A. D. Schwarz, C. Jones, P. Mountford, S Aldridge, Organometallics 2015, 34, 2126-2129; e) A. V. Protchenko, J. I. Bates, L. M. A. Saleh, M. P. Blake, A. D. Schwarz, E. L. Kolychev, A. L. Thompson, C. Jones, P. Mountford, S. Aldridge, J. Am. Chem. Soc. 2016, 138, 4555-4564; f) A. Rit, J. Campos, H. Niu, S. Aldridge, Nature Chem. 2016, 8, 1022-1026.

[14] As the $\left[\mathrm{Li}_{9} \mathrm{In}_{6}{ }_{6}(\text { boryl })_{6}(\mathrm{Cl})(\mathrm{OH})_{13}\right]^{+}$salt (the lithium is carried through from the use of boryllithium in preparation of the $(\text { boryl })_{2} \mathrm{InCl}$ starting material).

[15] a) C. Klemp, R. Köppe, E. Weckert, H. Schnöckel, Angew. Chem., Int Ed. 1999, 38, 1739-1743; b) C. Klemp, M. Bruns, J. Gauss, U Häussermann, G. Stösser, L. van Wüllen, M. Jansen, H. Schnöckel, J. Am. Chem. Soc. 2001, 123, 9099-9106; c) A. Schnepf, R. Köppe, E Weckert, H. Schnöckel, Chem.-Eur. J. 2004, 10, 1977-1981.

[16] M. Asay, C. Jones, M. Driess, Chem. Rev. 2011, 111, 354-396.

[17] For earlier examples of group 13 boryl complexes see references $11 \mathrm{p}$ and 11q, and: a) N. Dettenrieder, H. M. Dietrich,C. Schädle, C. MaichleMössmer, K. W. Törnroos, R. Anwander, Angew. Chem. Int. Ed. 2012, 51, 4461-4465; b) N. Dettenrieder, C. Schädle, C. Maichle-Mössmer, P. Sirsch, R. Anwander, J. Am. Chem. Soc. 2014, 136, 886-889.

[18] F. T. Edelmann, Coord. Chem. Rev. 194, 137, 403-481.

[19] For an example of B-B bond formation via the reaction of the same boryllithium nucleophile with a boron halide electrophile see: $Y$. Hayashi, Y. Segawa, M. Yamashita, K. Nozaki, Chem. Commun. 2011, 47, 58885890 .

[20] See, for example: A. J. Downs in The Group 13 Metals Aluminium, Gallium, Indium and Thallium: Chemical Patterns and Peculiarities (Eds. S. Aldridge, A. J. Downs), Wiley, Chichester, 2011.

[21] B. Twamley, P. P. Power, Angew. Chem. Int. Ed. 2000, 39, 3500-3503.

[22] N. Wiberg, T. Blank, M. Westerhausen, S. Schneiderbauer, H. Schnöckel, I. Krossing, A. Schnepf, Eur. J. Inorg. Chem. 2002, 351-356

[23] See also: B. Quillian, P. Wei, C. S. Wannere, P. v. R. Schleyer, G. H. Robinson, J. Am. Chem. Soc. 2009, 131, 3168-3169.

[24] Z. Chen, C. S. Wannere, C. Corminboeuf, R. Putcha, P. v. R. Schleyer, Chem. Rev. 2005, 105, 3842-3888.

[25] $\operatorname{NICS}(0)$ values of $-23.4,-18.5$ and -17.6 have been reported for the model systems $\left[\mathrm{E}_{3} \mathrm{H}_{3}\right]^{2-}(\mathrm{E}=\mathrm{B}, \mathrm{Al}, \mathrm{Ga}$, respectively), using a method which gives a value for benzene of $-11.5 .^{[8 a]}$

[26] a) V. Y Lee, K. Takanashi, T. Matsuno, M. Ichinohe, A. Sekiguchi, J. Am. Chem. Soc. 2004, 126, 4758-4759. See also b) K. Suzuki, T. Matsuo, D. Hashizume, H. Fueno, K. Tanaka, K. Tamao, Science 2011, 331, 1306-1309; c) S, Inoue, J. D. Epping, E. Irran, M. Driess, J. Am. Chem. Soc. 2011, 133, 8514-8517. 


\section{COMMUNICATION}

Reduction of indium boryl complexes to give 2- and 3-D aggregates can be controlled by the choice of supporting ligand. The unprecedented nanoscale cluster $\left[\ln _{68}(\text { boryl })_{12}\right]^{-}$

$\left(\ln _{12} @ \ln _{44} @ \ln _{12}(\text { boryl })_{12}\right)$ is isolated from the potassium reduction of a bis(boryl) precursor, while reduction of (amidinate) $\mathrm{In}{ }^{\mathrm{III}} \mathrm{Br}$ (boryl) gives a (weakly aromatic) planar tetranuclear $\left[\ln _{4}(\text { boryl })_{4}\right]^{2-}$ system.
Andrey V. Protchenko, Juan Urbano, Joseph A. B. Abdalla, Jesús Campos, Dragoslav Vidovic, Andrew D. Schwarz, Matthew P. Blake, Philip Mountford, Cameron Jones, and Simon Aldridge*

Page No. - Page No.

Electronic delocalization in two and three dimensions: differential aggregation in indium 'metalloid' clusters 